\title{
EFFECTS OF PERIOPERATIVE RESPIRATORY REHABILITATION IN LUNG CANCER RESECTION: A PILOT STUDY
}

Di Iulio Antonella ${ }^{1}$, D’Aurizio Carlo 2 , Damiani Marzia ${ }^{3}$, Casaccia Marco ${ }^{4}$, De Filippis Antonio Fabio 5

${ }^{1}$ MSc, U.O.C. Thoracic Surgery. "Santo Spirito" Hospital Pescara, ASL Pescara (Pescara-IT).

${ }^{2} M D$, Physical Medicine and Rehabilitation Specialist, Director of U.O.C. of Physical Medicine and Rehabilitation of the Hospital of Popoli (Pescara-IT); Local Health Company ASL Pescara (Pescara-IT).

${ }^{3}$ MSc, PP.OO. Organization of Technical Rehabilitation Activities, Territorial Services of the Area ASL Pescara (Pescara-IT).

${ }^{4}$ MD, Thoracic Surgery, Director F.F. U.O.C. Thoracic Surgery. "Santo Spirito” Hospital Pescara, ASL Pescara (Pescara-IT).

${ }^{5}$ MD, Thoracic Surgery, Thoracic Surgery. “Santo Spirito” Hospital Pescara, ASL Pescara (Pescara-IT).

KEYWORDS: Pulmonary Rehabilitation, Lung Cancer, Physiotherapy

\section{ABSTRACT}

The aim of this study is to evaluate the impact of short term Preoperative Respiratory Rehabilitation (PRR) on the changes of respiratory functions and clinical conditions in patients with malignant lung cancer lesion and reduced respiratory functions, with high risk to develop postoperative pulmonary complications (PPCs). A total of 15 patients were treated with PRR protocol. The rehabilitation programme was concluded by all patients. They showed a statistically significant improvement of lung functionality Forced Vital Capacity $(F V C)(p=0,004)$, Forced Expiration Value in the first second (FEV1) $(p<0,001)$ and walking distance $(p<0,001)$. In addition, there was a significant enhancement of Partial Oxygen Saturation (SpO2) $(p=0,002)$, Hart Rate $(H R)(p=0,002)$ and Borg Dyspnoea Scale values $(p=0,003)$ indicate a better cardiorespiratory functionality.

In conclusion a short feasible PRR is suitable in patients' candidate to thoracic surgery.

\section{INTRODUCTION}

Lung cancer is the most common cause of cancer mortality in males and females worldwide (Ferlay et al., 2010). Furthermore, the increase in global tobacco smoke leads to a rising of lung cancer mortality (Pesch et al., 2012). The treatment of lung cancer is based on surgery, radiation therapy, chemotherapy, and palliative care. These therapies may be used alone or in combination, in attempt to cure or manage the adverse effects of the malignant lung lesions (Bongers et al., 2012; Kim et al., 2012). The complete surgical resection is currently the only curative treatment for lung cancer. However, many of those patients are also affected by chronic obstructive pulmonary disease (COPD) (Ciatkowska-Rysz et al., 2012; Loganathan et al., 2006) which increases their risk of PPCs and their likelihood of being considered inoperable (Benzo et al., 2012; Agostini et al., 2010; Sekine et al., 2002). Physiotherapy has been used in prevention and treatment of major surgery complications since 1960s. Indeed, PPCs are an important cause of discomfort and morbidity for patients and lead to a longer intensive care and hospital stay (Reeve et al., 2010; Zehr et al., 1998; Taylor et al., 1990). There are evidence supporting the efficacy of Respiratory Rehabilitation (RR) in the global management of patients with respiratory disease and RR programs are practiced worldwide (Troosters et al., 2005). Moreover, the role of $\mathrm{RR}$ in the preoperative setting has been widely investigated in patient with pulmonary disease candidate for lung resection surgery and it is considered a crucial component in the treatment strategy of patient with high surgical risk (Pasqua et al., 2013; Singh et al., 2013; Celli, 2004). PRR has been suggested as an intervention to reduce surgical morbidity but there is not jet an established treatment protocol (Benzo et al., 2012). The aim of this study is to evaluate the impact of short term PRR on the changes of respiratory functions and clinical conditions in patients with malignant lung cancer lesion and reduced respiratory functions, with high risk to develop PPCs.

\section{METHODS AND MATERIALS Population}

This pilot study took place in the Department of Thoracic Surgery at "Santo Spirito" Civil Hospital, Pescara (Italy), from January to April 2018. To be eligible for enrolment in this study, patients should be enlisted for pulmonary resection surgery for lung cancer with FEV1 lower than 61\% (Agostini et al. 2010; Licker et al., 2006). A total of 15 patients were included (Table 1). All the patients gave informed written consent to the experimental procedure, which was in accordance with the latest revision of the Helsinki Declaration for Human Research and with the procedures concerning the privacy protection of subjects participating in biomedical research, as defined by ISO 9001 standards for research and experimentation.

\section{Rehabilitation protocol}

All patients were evaluated at admission (T0) and before surgery (T1). The rehabilitation protocol started on the day of admission in hospital and lasted on average after 6 days (until the operation day). In addi- 
Table I - Baseline characteristics of the study group

Numero di pazienti/Number of patients

15

Età media (anni)/Mean age (years)

$72,93 \pm 9,75$

Genere/Gender

Maschi/Male

Femmine/Female

Fumatori/Smokers

Media FVC ${ }^{1}$, litri (\%)/Mean FVC ${ }^{1}$, litres (\%)

Media FEV1 ${ }^{2}$, litri (\%)/Mean FEV1 ${ }^{2}$, litres (\%)

FEV1 $^{2}$ (stratificazione)/FEV1 ${ }^{2}$ (stratification)

$<50 \%$

$50 \%<\mathrm{x}<60 \%$

$60 \%<\mathrm{x}<70 \%$

$70 \%<\mathrm{x}<80 \%$

Media $6 \mathrm{MWT}^{3}$ valori/Mean 6MWT $^{3}$ values

Distanza cammino Metri/Walking distance (Meters)

$181,80 \pm 68,19 \mathrm{SpO}_{2}{ }^{4} \%$

Basale/Basal

$97,00 \pm 1,41$

Fine del test/End of test

$96,07 \pm 2,28$

$\underline{\mathrm{HR}}^{\underline{5}} \underline{\mathrm{bpm}^{6}} \underline{\mathrm{HR}^{5}} \underline{\mathrm{bpm}^{6}}$

Basale/Basal

$80,40 \pm 9,55$

Fine del test/End of test

$92,60 \pm 11,50$

Scala Borg Modificata (Dispnea)/Borg Modified Scale (Dyspnoea)

Basale/Basal $0,13 \pm 0,23$

Fine del test/End of test

$0,77 \pm 1,07$

Operazione prevista/Foreseen operation

Bilobectomia/Bilobectomy

Resezione a doppio cuneo/Double wedge resection

Lobectomia/Lobectomy

Pneumonectomia/Pneumonectomy

Resezione cuneiforme/Wedge resection

$\begin{array}{ll}1 & 6,70 \% \\ 2 & 13,30 \% \\ 8 & 53,30 \% \\ 2 & 13,30 \% \\ 2 & 13,30 \%\end{array}$

Note: ${ }^{1} \mathrm{FVC}=$ Capacità Vitale Forzata, ${ }^{2} \mathrm{FEV} 1=$ Volume Espiratorio Forzato nel primo secondo, ${ }^{3} 6 \mathrm{MWT}=6 \mathrm{Minutes}$ Walk Test, ${ }^{4} \mathrm{SpO}_{2}=$ Saturazione parziale di Ossigeno, ${ }^{5} \mathrm{HR}=$ Ritmo Cardiaco, ${ }^{6} \mathrm{bpm}=$ battiti per minuto.

Notes: ${ }^{1} \mathrm{FVC}=$ Forced Vital Capacity, ${ }^{2} \mathrm{FEV} 1=$ Forced Expiration Volume in the 1 st second, ${ }^{3} 6 \mathrm{MWT}=6$ Minutes

Walk Test, ${ }^{4} \mathrm{SpO}_{2}=$ partial Oxygen Saturation, ${ }^{5} \mathrm{HR}=$ Heart Rate, ${ }^{6} \mathrm{bpm}=$ beats per minute.

Tab. 1

tion to PRR, all patients received optimization of the pharmacological treatment and smoking cessation. Patients were educated to practice deep and slow breathing (deep respiration cycle with prolonged expiration with half closed lips) (Raupach et al., 2008; Westerdahl et al., 2005). Deep and slow breathing helps the removal of secretion and thoracic mobility, highlighting relaxes and dyspnoea control (Hillegass et al., 2001; Hough, 2001). Patients were also trained in mobilization exercises for thorax and the using of respiratory devices (1. Acapella ${ }^{\circledR}$ Choice Vibratory PEP Device, Smiths Medical ASD; Coach 2 ® Incentive Spirometer $4000 \mathrm{ml}$, Smiths Medical).

In the morning patients were supervised by the physiotherapist during the execution of deep and slow breathing (30 repetitions), during the exercise with respiratory devices (30 repetitions for each device) and in the mobilization exercises for thorax (30 minutes). Then patients underwent cardiorespiratory incremental training on treadmill. Time and speed initially showed in. During the cardiorespiratory training HR, SpO2 and Dyspnoea (Borg Scale) was monitored. In the afternoon, patients were instructed to perform breathing exercises and respiratory devic- es. The self-treatment program was organized in five afternoon sessions, one every hour approximately. Each session consisted of: deep and slow breathing (at least 10 repetitions) and exercise with respiratory devices (at least 10 repetitions for each device). In addition, patients should walk in the thoracic ward for 20 minutes in the first 3 days, and 30 minutes in the last 3 days, or alternatively 3000 steps every day (step countered).

\section{Outcome measures}

Outcome measures were respiratory functions evaluated with spirometry (Spirolab III ver. 3.4) in particular, FVC and FEV1; functional capacity measured with 6 Minute Walk Test (6MWT) according to American Thoracic Society recommendations (ATS Committee, 2002). In order to evaluate the quality of the postoperative course we compared our study group with a representative control group of patients admitted in the same Department of Thoracic Surgery at "Santo Spirito" Civil Hospital - Pescara (Italy), from January to April 2017 (same period of the study group, but one year before). From the clinic records and inclusion criteria it was selected 17 patients (Table 2). This group did not receive PRR. 
Table II - Baseline characteristics of the control group

Numero di pazienti/Number of patients

Età media (anni)/Mean age (years)

Genere/Gender

Maschi/Male

Femmine/Female

Media FVC ${ }^{1}$, litri (\%)/Mean FVC 1 , litres (\%)

Media FEV1 ${ }^{2}$, litri (\%)/Mean FEV1 ${ }^{2}$, litres (\%)

Operazione prevista/Foreseen operation

Lobectomia/Lobectomy

Resezione a doppio cuneo/Double wedge resection

Lobectomia e pleurectomia/Lobectomy e pleurectomy

Pneumectomia/Pneumonectomy

Resezione cuneiforme/Wedge resection

Bilobectomia/Bilobectomy
17

$65,41 \pm 12,32$

$\begin{array}{lr}13 & 76,5 \% \\ 4 & 23,5 \% \\ 2,62 \pm 0,75 & (79,18 \pm 16,55 \%) \\ 2,35 \pm 0,62 & (89,06 \pm 16,60 \%)\end{array}$

$5 \quad 29,41 \%$

$211,76 \%$

$211,76 \%$

$2 \quad 11,76 \%$

$4 \quad 23,53 \%$

$211,76 \%$

Note: ${ }^{1} \mathrm{FVC}=$ Capacità Vitale Forzata, ${ }^{2} \mathrm{FEV} 1=$ Volume Espiratorio Forzato nel primo secondo.

Notes: ${ }^{1} \mathrm{FVC}=$ Forced Vital Capacity, ${ }^{2} \mathrm{FEV} 1=$ Forced Expiration Volume in the 1 st second.

Tab. 2

Table III - Outcomes after PRRI before surgery (mean values)

Lunghezza dell'ospedalizzazione (giorni)/Length of hospital stay (days) $\quad \mathbf{1 4 , 8 7 \pm 5 , 8 3}$

Pazienti con $\mathrm{PPCs}^{2} / \mathrm{Patients} \mathrm{with}^{\mathrm{PPC}}{ }^{2}$

FVC $^{3}$, litri (\%)/FVC ${ }^{3}$, litres (\%)

$2,11 \pm 0,49(72,67 \pm 12,65)$ media miglioramento, litri (\%)/mean improvement, litres (\%)

FEV1 4 , litri (\%)/FEV1 ${ }^{4}$, litres (\%)

$1,61 \pm 0,20(69,00 \pm 4,61)$

media miglioramento, litri (\%)/mean improvement, litres (\%)

6MWT $^{5}$ valori/6MWT ${ }^{5}$ values

Distanza cammino (metri)/Walking Distance (meters) $\quad 270,00 \pm 113,95 \quad p<0,001$ media miglioramento (metri)/mean improvement (meters) $\quad+88,20$

$\mathrm{SpO}_{2} \underline{6} \% / \mathrm{SpO}_{2} \underline{6} \%$

Basale/Basal

media miglioramento/mean improvement

Fine del test/End of test $p=0,002$

$\underline{\operatorname{HR}}^{\underline{7}} \underline{\mathrm{bpm}^{8}}$

media miglioramento/mean improvement

$$
\begin{array}{ll}
97,73 \pm 1,16 & p=0,046 \\
& +0,73 \\
& 97,53 \pm 1,30 \\
& +1,47
\end{array}
$$

Basale/Basal

media miglioramento/mean improvement

Fine del test/End of test media miglioramento/mean improvement

Borg Modified Scale (Dyspnoea)

Basale/Basal media miglioramento/mean improvement

Fine del test/End of test media miglioramento/mean improvement

$$
\begin{array}{ll}
77,20 \pm 8,10 & p=0,015 \\
86,13 \pm 10,22 & -3,20 \\
& p=0,002 \\
& -6,47
\end{array}
$$

$\begin{array}{ll}0,03 \pm 0,13 & \text { n.s. } \\ 0,23 \pm 0,42 & -0,10 \\ & p=0,003 \\ & -0,87\end{array}$

Note: Il $p$ value si riferisce alla differenza tra pre e post riabilitazione ed è ottenuto mediante Wilcoxon's signed rank test (paired sample). ${ }^{1} \mathrm{PRR}=$ riabilitazione respiratoria preoperatoria,${ }^{2} \mathrm{PPCs}=$ complicazioni polmonari postoperatorie, ${ }^{3} \mathrm{FVC}=$ Capacità Vitale Forzata, ${ }^{4} \mathrm{FEV} 1=$ Volume Espiratorio Forzato nel primo secondo, ${ }^{5} 6 \mathrm{MWT}=6$ Minutes Walk Test, ${ }^{6} \mathrm{SpO}_{2}=$ Saturazione parziale di Ossigeno, ${ }^{7} \mathrm{HR}=$ Ritmo Cardiaco, ${ }^{8} \mathrm{bpm}=$ battiti per minuto.

Notes: The $p$ value is referred to the differences between pre and post rehabilitation and obtained with the Wilcoxon's signed rank test (paired sample). ${ }^{l} \mathrm{PRR}=$ preoperative respiratory rehabilitation, ${ }^{2} \mathrm{PPCs}=$ postoperative pulmonary complications, ${ }^{3} \mathrm{FVC}=$ Forced Volume Capacity, ${ }^{4} \mathrm{FEV} 1=$ Forced Expiration Volume in the 1 st second, ${ }^{5} 6 \mathrm{MWT}=6$ Minutes Walk Test, ${ }^{6} \mathrm{SpO}_{2}=$ partial Oxygen Saturation, ${ }^{7} \mathrm{HR}=$ Heart Rate, ${ }^{8} \mathrm{bpm}=$ beats per minute. 

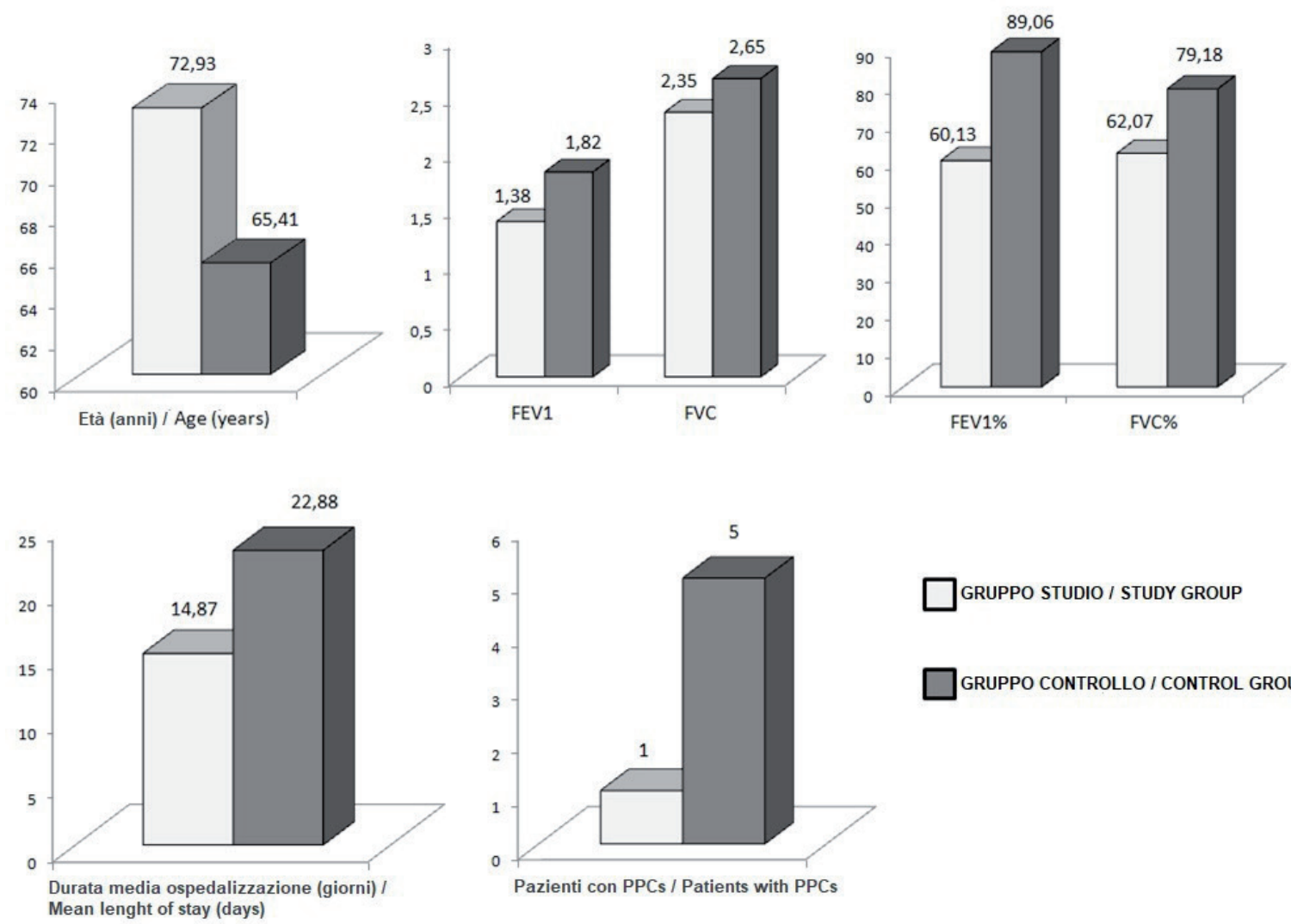

GRUPPO STUDIO / STUDY GROUP

GRUPPO CONTROLLO / CONTROL GROUP

Fig. 06.1. Comparison between the study group and the control group. Clinical conditions before surgery are shown in the first row of graphics. Outcome measures are shown in the second row of graphics.

\section{Statistical analysis}

Computations have been performed using the $\mathrm{NCSS}^{\circ}$ for Windows statistical software package $\left(\mathrm{NCSS}^{\circ}\right.$ LLC, version 9, Kaysville, UT). Data are expressed as mean \pm standard deviation (SD). Results were compared by Wilcoxon's signed rank test (paired sample), or by Wilcoxon's Rank Sum Test (two sample), or by Fisher's exact test. A $p$ value less than 0,05 was considered significant.

\section{RESULTS}

All 15 patients successfully completed the PRR protocol. There was a statistically significant increment in the FVC $(p=0,004)$, FEV1 $(p<0,001)$ which is crucial because of the eligibility of patient' surgery. A significant improvement recorded in all 6MWT parameters that is related to a better cardiorespiratory functionality (Table 3 ). The comparison between groups showed that the patients of representative control group were hospitalized for a longer period $(p<0,05)$ and a greater number of patients have been subject to PPCs (n.s.) (Figure 1). Only one patient of study group had PPCs (bronchial obstruction).

\section{DISCUSSION}

The development of a short and feasible PRR protocol is linked to the schedule needs that a Thoracic Surgery Unit requires in a Public Hospital. The positive impact of PRR was investigated in literature. The rehabilitation treatment included breathing exercises, endurance training and using of respiratory devices (Divisi et al., 2013; Mujovic et al., 2013; Bobbio et al., 2007; Cesario et al., 2007; Jones et al., 2007; Spruit et al., 2006). Considering a short period of rehabilitation before surgery, an interesting work comes from Sekine et al. (Sekine et al., 2005) reporting that a 2-week PRR starting on admission in hospital, reduced the length of stay of 22 patients. Again, in this perspective, another study comes from Yanez-Brage, which included 263 patients treated with thoracic surgery who received only one day of PRR (incentive spirometry, deep breathing, coughing exercises and education on early postoperative ambulation). This article proved that the incidence of postoperative atelectasis was significantly reduced to $50 \%$ (YanezBrage et al., 2009). Our protocol for patients with lung malignant tumour lesion, admitted and enlisted for thoracic surgery, with reduced respiratory functionality and at high risk for PPCs, showed interesting results about the respiratory functions and clinical postoperative status. It achieved a reduction of length of hospital stay and number of patients with PPCs, with significant decrement of expenses. A rehabilitation based on educational treatment is not enough (Reid et al., 2010). Indeed, this pilot study integrated aerobic and mobilization exercises, breathing and educational aspects in an intensive system were patients being supervised and self-treated. Anyway, the positive response we received from patients' diaries on supports the importance of their education. If correctly educated on how to perform the assignments, patients gained self confidence in their possibilities and abilities. They also became able to repeat them in the postoperative phase without problems or pain. This allows fostering their autonomy during the rehabilitation process and in preparation for surgery. In this hypothesis, patients were encouraged to become an active participant in this preparation program for the surgery. Self-efficacy has been identified as an important mediator of behavioural changes, especially 
in patients with COPD and cancer (Jerant et al., 2011; Lemmens et al., 2008; Van Weert et al., 2007). Furthermore, recent studies recommend promoting selfefficacy even during respiratory rehabilitation (Bentsen et al., 2010; Janssen et al., 2010). The practice of slow and deep breathing (reducing the respiratory ratio and prolonging expiration phase) showed benefits in patients with COPD, decreasing sympathetic tone (Raupach et al., 2008). In our experience, this practice leads the patients of the study group to better manage the postoperative pain (Friesner et al., 2006), improving the quality of the postoperative period (Kshettry et al., 2008). The cardiorespiratory aerobic training enhances cardio respiratory functions with important implications for the postoperative course (Jones et al.,
2007). The positive results in a short feasible PRR protocol, which could become a useful method to improve functional status for inpatients enlisted for thoracic surgery. Further trials, with a larger number of patients, could corroborate these findings, and also include the assessment of the follow up of the patients.

\section{CONCLUSIONS}

In conclusion, a short feasible PPR protocol for patients with lung malignant tumour lesion, admitted and enlisted for thoracic surgery, with reduced respiratory functionality and at high risk for PPCs could be considered as an efficient treatment for the optimization of the status of patients both pre and post thorax surgery.

\section{REFERENCES}

1. Agostini, P., Cieslik, H., Rathinam, S., Bishay, E., Kalkat, et al. (2010). Postoperative pulmonary complications following thoracic surgery: are there any modifiable risk factors?. Thorax, 65(9), 815-818.

2. Laboratories ATSCoPSfCPF. (2002). ATS statement: guidelines for the six-minute walk test. Am J Respir Crit Care Med, 166(1), 111-117.

3. Cesario, A., Ferri, L., Galetta, D., Cardaci, V., Biscione, G., et al. (2007). Pre-operative pulmonary rehabilitation and surgery for lung cancer. Lung Cancer, 57(1), 118-119.

4. Ciałkowska-Rysz, A., Kowalczyk, M., Gottwald, L., \& Kaźmierczak-Łukaszewicz, S. (2012). The comparison of common cancer types and the coincidence of concomitant chronic diseases between palliative home care patients in Lodz Voivodeship and the general Polish population. Archives of medical science: AMS, 8(3), 496.

5. Celli, B. R. (2004). Chronic respiratory failure after lung resection: the role of pulmonary rehabilitation. Thoracic surgery clinics, 14(3), 417-428.

6. Bentsen, S. B., Wentzel-Larsen, T., Henriksen, A. H., Rokne, B., \& Wahl, A. K. (2010). Self-efficacy as a predictor of improvement in health status and overall quality of life in pulmonary rehabilitation-An exploratory study. Patient education and counseling, 81(1), 5-13.

7. Benzo, R., Wigle, D., Novotny, P., Wetzstein, M., Nichols, F., et al. (2011). Preoperative pulmonary rehabilitation before lung cancer resection: results from two randomized studies. Lung cancer, 74(3), 441-445.

8. Bobbio, A., Chetta, A., Ampollini, L., Primomo, G. L., Internullo, E., et al. (2008). Preoperative pulmonary rehabilitation in patients undergoing lung resection for non-small cell lung cancer. European journal of cardio-thoracic surgery, 33(1), 95-98.

9. Bongers, M. L., Coupé, V. M., Jansma, E. P., Smit, E. F., \& Uyl-de Groot, C. A. (2012). Cost Effectiveness of Treatment with New Agents in Advanced Non-Small-Cell Lung Cancer. Pharmacoeconomics, 30(1), 17-34.

10. Divisi, D., Di Francesco, C., Di Leonardo, G., \& Crisci, R. (2013). Preoperative pulmonary rehabilitation in patients with lung cancer and chronic obstructive pulmonary disease. European Journal of Cardio-Thoracic Surgery, 43(2), 293-296.

11. HR, Ferlay, J. S., Bray, F., Forman, D., Mathers, C., \& Parkin, D. M. (2010). Estimates of worldwide burden of cancer in 2008: GLOBOCAN 2008. Int J Cancer, 127(12), 2893-917.

12. Friesner, S. A., Curry, D. M., \& Moddeman, G. R. (2006). Comparison of two pain-management strategies during chest tube removal: relaxation exercise with opioids and opioids alone. Heart \& lung, 35(4), 269-276.

13. Hillegass, E.A., \& Sadowsky, H.S. (2001). Essentials of cardiopulmonary physical therapy, 2nd edition. W.B. Saunders Company.

14. Hough, A. (2001). Physiotherapy in respiratory care: an evidence-based approach to respiratory and cardiac management. Nelson Thornes.

15. Janssen, D. J., Engelberg, R. A., \& Curtis, J. R. (2010). Toward patient-tailored education in COPD.

16. Jerant, A., Franks, P., \& Kravitz, R. L. (2011). Associations between pain control self-efficacy, self-efficacy for communicating with physicians, and subsequent pain severity among cancer patients. Patient education and counseling, $85(2), 275-280$.

17. Jones, L. W., Peddle, C. J., Eves, N. D., Haykowsky, M. J., Courneya, K. S., et al. (2007). Effects of presurgical exercise training on cardiorespiratory fitness among patients undergoing thoracic surgery for malignant lung lesions. Cancer: Interdisciplinary International Journal of the American Cancer Society, 110(3), 590-598.

18. Kim, A. W., Boffa, D. J., Wang, Z., \& Detterbeck, F. C. (2012). An analysis, systematic review, and meta-analysis of the perioperative mortality after neoadjuvant therapy and pneumonectomy for non-small cell lung cancer. The Journal of thoracic and cardiovascular surgery, 143(1), 55-63. 
19. Kshettry, V. R., Carole, L. F., Henly, S. J., Sendelbach, S., \& Kummer, B. (2006). Komplementarne alternativne medicinske terapije za pacijente operacije srca: izvodljivost, sigurnost i utjecaj. Ann Thorac Surg, 81(1), 201-5.

20. Lemmens, K. M. M., Nieboer, A. P., \& Huijsman, R. (2008). Designing patient-related interventions in COPD care: empirical test of a theoretical model. Patient education and counseling, 72(2), 223-231. .

21. Licker, M. J., Widikker, I., Robert, J., Frey, J. G., Spiliopoulos, A., et al. (2006). Operative mortality and respiratory complications after lung resection for cancer: impact of chronic obstructive pulmonary disease and time trends. The Annals of thoracic surgery, 81(5), 1830-1837.

22. Loganathan, R. S., Stover, D. E., Shi, W., \& Venkatraman, E. (2006). Prevalence of COPD in women compared to men around the time of diagnosis of primary lung cancer. Chest, 129(5), 1305-1312.

23. Mujovic, N., Mujovic, N., Subotic, D., Marinkovic, M., Milovanovic, A., et al. (2014). Preoperative pulmonary rehabilitation in patients with non-small cell lung cancer and chronic obstructive pulmonary disease. Archives of medical science: $A M S, 10(1), 68$.

24. Pasqua, F., Geraneo, K., Nardi, I., Lococo, F., \& Cesario, A. (2015). Pulmonary Rehabilitation in lung cancer. Monaldi Archives for Chest Disease, 79(2).

25. Pesch, B., Kendzia, B., Gustavsson, P., Jöckel, K. H., Johnen, G., et al. (2012). Cigarette smoking and lung cancerrelative risk estimates for the major histological types from a pooled analysis of case-control studies. International journal of cancer, 131(5), 1210-1219.

26. Raupach, T. (2008). Bahr F, Herrmann P, Luethje L, Heusser K, Hasenfuss G, Bernardi L, Andreas S. Slow breathing reduces sympathoexcitation in COPD. Eur Respir J, 32, 387-392.

27. Singh, F., Newton, R. U., Galvão, D. A., Spry, N., \& Baker, M. K. (2013). A systematic review of pre-surgical exercise intervention studies with cancer patients. Surgical oncology, 22(2), 92-104.

28. Reeve, J. C., Nicol, K., Stiller, K., McPherson, K. M., Birch, P., et al. (2010). Does physiotherapy reduce the incidence of postoperative pulmonary complications following pulmonary resection via open thoracotomy? A preliminary randomised single-blind clinical trial. European journal of cardio-thoracic surgery, 37(5), 1158-1166.

29. Reid, J. C., Jamieson, A., Bond, J., Versi, B. M., Nagar, A., et al. (2010). A pilot study of the incidence of post-thoracotomy pulmonary complications and the effectiveness of pre-thoracotomy physiotherapy patient education. Physiotherapy Canada, 62(1), 66-74.

30. Sekine, Y., Behnia, M., \& Fujisawa, T. (2002). Impact of COPD on pulmonary complications and on long-term survival of patients undergoing surgery for NSCLC. Lung Cancer, 37(1), 95-101.

31. Sekine, Y., Chiyo, M., Iwata, T., Yasufuku, K., Furukawa, S., et al. (2005). Perioperative rehabilitation and physiotherapy for lung cancer patients with chronic obstructive pulmonary disease. The Japanese Journal of Thoracic and Cardiovascular Surgery, 53(5), 237-243.

32. Spruit, M. A., Janssen, P. P., Willemsen, S. C., Hochstenbag, M. M., \& Wouters, E. F. (2006). Exercise capacity before and after an 8-week multidisciplinary inpatient rehabilitation program in lung cancer patients: a pilot study. Lung cancer, 52(2), 257-260.

33. Taylor, G. J., Mikell, F. L., Moses, H. W., Dove, J. T., Katholi, R. E., et al. (1990). Determinants of hospital charges for coronary artery bypass surgery: the economic consequences of postoperative complications. The American journal of cardiology, 65(5), 309-313.

34. Troosters, T., Casaburi, R., Gosselink, R., \& Decramer, M. (2005). Pulmonary rehabilitation in chronic obstructive pulmonary disease. American journal of respiratory and critical care medicine, 172(1), 19-38.

35. van Weert, E., Hoekstra-Weebers, J. E., May, A. M., Korstjens, I., Ros, W. J., \& van der Schans, C. P. (2008). The development of an evidence-based physical self-management rehabilitation programme for cancer survivors. Patient education and counseling, 71(2), 169-190.

36. Westerdahl, E., Lindmark, B., Eriksson, T., Hedenstierna, G., \& Tenling, A. (2005). Deep-breathing exercises reduce atelectasis and improve pulmonary function after coronary artery bypass surgery. Chest, 128(5), 3482-3488.

37. Yánez-Brage, I., Pita-Fernández, S., Juffé-Stein, A., Martínez-González, U., Pértega-Díaz, S., \& Mauleón-García, Á. (2009). Respiratory physiotherapy and incidence of pulmonary complications in off-pump coronary artery bypass graft surgery: an observational follow-up study. BMC pulmonary medicine, 9(1), 36.

38. Zehr, K. J., Dawson, P. B., Yang, S. C., \& Heitmiller, R. F. (1998). Standardized clinical care pathways for major thoracic cases reduce hospital costs. The Annals of thoracic surgery, 66(3), 914-919. 